\title{
Increasing activity and improving nutrition through a schools- based programme: Project Energize. 1. Design, programme, randomisation and evaluation methodology
}

\author{
David Graham ${ }^{1,2, *}$, Sarah Appleton ${ }^{2}$, Elaine Rush ${ }^{3}$, Stephanie McLennan ${ }^{4}$, Peter Reed ${ }^{1}$ \\ and David Simmons 5 \\ 'Waikato Clinical School, Faculty of Medical \& Health Sciences, University of Auckland, Auckland, New \\ Zealand: ${ }^{2}$ Child Health, Waikato Hospital, PO Box 3200, Hamilton, New Zealand: ${ }^{3}$ Centre for Physical Activity \\ and Nutrition Research, Faculty of Health and Environmental Sciences, Auckland University of Technology, \\ Auckland, New Zealand: ${ }^{4}$ Sport Waikato, Hamilton, New Zealand: ${ }^{5}$ Institute of Metabolic Science, Cambridge \\ University Hospitals NHS Foundation Trust, Cambridge, UK
}

Submitted 21 November 2006: Accepted 1 November 2007: First published online 15 January 2008

\begin{abstract}
Project Energize is a through-school nutrition and activity programme that is being evaluated in a 2-year, cluster-randomised, longitudinal study. The present paper describes the background of the programme and study, the programme development and delivery, the study methodology including randomisation, measurement and analysis tools and techniques, and the mix of the study population. The programme is being delivered to sixty-two primary schools with sixty-two control schools, each limb containing about 11000 students. The children in the evaluation cohort are 5 or 10 years old at enrolment; the randomisation protocol has achieved post-consent enrolment of 3000 evaluation participants, who are comparable by age, sex and school decile. End-point measures include body composition and associated physical characteristics, fitness, home and school environment and practice.
\end{abstract}

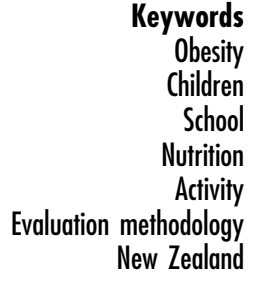

Internationally there is strong evidence that the prevalence of childhood obesity is increasing ${ }^{(1)}$. New Zealand childhood obesity rates are consistent with international figures $^{(2)}$, and show worsening trends over time ${ }^{(3)}$. Childhood obesity is predictive of adult obesity, with associated cardiovascular, respiratory, neurovascular and endocrine morbidity and mortality ${ }^{(4)}$. Internationally, there are higher rates of overweight and obesity among children from some ethnic groups ${ }^{(5,6)}$ and this finding holds true in New Zealand for Māori and Pacific Islands children $^{(2,3,7)}$. While there is increasing literature on associations with childhood obesity in terms of causation and potential treatment, there is little information on effective long-term prevention of childhood obesity or its sequelae $^{(8)}$. The rise in obesity rates and associated morbidity seen throughout the Western world from the mid-20th century ${ }^{(1-3)}$ has generally been ascribed to a number of factors ${ }^{(9)}$. Social changes including industrialisation and automation leading to a decrease in energy expenditure, greater access to increasing portions of high-energy foods and reduction in extended breastfeeding provide the setting in which complex biological systems are challenged to maintain an appropriate balance. A reductionist view of the cause, and therefore of the potential interventions, is one of too great an energy intake for energy expenditure, perhaps complicated by a relative imbalance of essential dietary components ${ }^{(10)}$.

Early large and long-term community-based interventions to date have shown little effect ${ }^{(11)}$. This may be either because biological drives to store and maintain energy $^{(12-14)}$ (once an evolutionary advantage) are now excessive, or because current economic, socio-cultural and environmental forces are too great for single-factor changes to be effective ${ }^{(15)}$. Social-ecological models have been developed allowing an understanding of potential contributing factors impacting on both activity $^{(16)}$ and nutrition ${ }^{(17)}$. There appear to be critical periods in childhood where adverse factors are associated with higher levels of adult morbidity and mortality, and these may present opportunities for positive intervention $^{(18-20)}$.

It has been argued that a comprehensive throughschool programme in partnership with health promotion services, with curricular, co-curricular and extracurricular elements, would be more likely to succeed. Interventions in both the school setting and the family setting have been proposed, and single-intervention trials in both settings have been evaluated with limited success ${ }^{(21)}$. 
While long-term data are limited, there is piecemeal evidence from a range of short-term studies that both simple and intensive school-based and through-school nutrition and/or activity interventions can change practices and outcomes ${ }^{(22-31)}$.

In the New Zealand setting, there is a need for an intervention that is 'do-able', i.e. able to be implemented through current school systems, without requirements for excessive extracurricular effort, without impinging on the already intense school curriculum requirements, and utilising available school and community resources. An in-school and through-school approach meets this criterion, particularly if incorporating key aspects of the Health Promoting Schools initiative ${ }^{(32)}$, and utilising curricular, co-curricular and extracurricular change opportunities.

The New Zealand Government, through the Healthy Eating - Healthy Action strategy ${ }^{(33)}$, has committed to a range of interventions in an attempt to address concerns over increasing obesity and associated burdens on the health system. While laudable, there is little solid evidence that implementation of the strategy will have the desired effect, and formal evaluation has not yet been developed. In 2004, the Waikato District Health Board (WDHB) decided to invest in a through-school child health initiative to improve nutrition and physical activity and reduce adiposity among 5-and 10-year-old students, accompanied by structured evaluation. The present paper describes the Project Energize programme and evaluation design.

\section{Evaluation methodology}

Project Energize has been developed as a through-school programme to improve childhood obesity, cardiovascular risk factors, bone health and dental health. The Project Energize evaluation is a 2-year, stratified, randomised controlled, longitudinal study of this school-based nutrition and activity programme implemented in primary schools in Waikato, New Zealand.

The Waikato region is in the upper North Island of New Zealand. The regional demographics ${ }^{(34)}$ are shown in Table $1^{(35)}$. While the Waikato region has relatively few Pacific Islands children (2262 in total), these are predominantly in the urban areas of Hamilton City and Tokoroa.

The evaluation was designed to: (i) identify and measure childhood body composition, related health parameters, environmental associations and risk factors; (ii) evaluate whether it is possible to implement a school-based nutrition and activity programme to address modifiable risk factors; (iii) evaluate whether the programme changes the modifiable risk factors; and (iv) determine whether this is associated with a change in child obesity and related health outcomes. The evaluation cohort is children who are 5 or 10 years of age at enrolment, prior to programme commencement.

Having documented the baseline rate of obesity, dental status, fitness and a number of general health parameters,
Table 1 Waikato and New Zealand childhood demography

\begin{tabular}{lrr}
\hline & & \\
& Waikato & Zealand \\
\hline Total no. of children aged 5-14 years & 52668 & 576982 \\
NZ European (\%) & $62 \cdot 3$ & $59 \cdot 9$ \\
Māori (\%) & $31 \cdot 2$ & $22 \cdot 3$ \\
Pacific (\%) & $3 \cdot 0$ & $7 \cdot 9$ \\
Asian/Indian & $3 \cdot 5$ & $6 \cdot 0$ \\
Other/Not stated (\%) & $3 \cdot 3$ & $3 \cdot 9$ \\
Rural (\%) & $65 \cdot 5$ & $39 \cdot 8$ \\
Urban (\%) & $34 \cdot 5$ & $60 \cdot 2$ \\
NZDep2001 decile 8-10 (\%) & $39 \cdot 8$ & $34 \cdot 2$ \\
NZDep2001 decile 8-10 NZ European (\%) & $42 \cdot 5$ & $35 \cdot 9$ \\
NZDep2001 decile 8-10 Māori (\%) & $45 \cdot 2$ & $37 \cdot 6$ \\
NZDep2001 decile 8-10 Pacific (\%) & $5 \cdot 1$ & $17 \cdot 0$ \\
NZDep2001 decile 8-10 Asian/Indian (\%) & $3 \cdot 0$ & $5 \cdot 1$ \\
NZDep2001 decile 8-10 Other/Not stated (\%) & $4 \cdot 2$ & $4 \cdot 5$ \\
\hline
\end{tabular}

NZDep2001 combines nine variables from the 2001 census which reflect eight dimensions of deprivation. NZDep2001 provides a deprivation score for each meshblock in New Zealand. Meshblocks are geographical units defined by Statistics New Zealand, containing a median of approximately ninety people in 2001. The NZDep2001 index of deprivation ordinal scale ranges from 1 to 10 , where 1 represents the areas with the least deprived scores and 10 the areas with the most deprived scores ${ }^{(35)}$.

the study also aims to identify associations with these morbidities (in particular, nutrition, activity levels, home and school resources and practices) as well as potentially modifiable environmental and behavioural factors. Endpoint evaluation of this programme will determine the change in health parameters and their determinants.

\section{Ethics approval}

This evaluation was approved by the Waikato (now Northern Y) Ethics Committee. This required both the usual caregiver and the child (including children in the 5 -year-old cohort) providing signed informed consent.

\section{Randomisation of schools}

A list of all primary schools in the WDHB catchment was provided by the Ministry of Education, characterised by location and size of school, ethnicity of students, and school decile. A school's decile, determined nationally and with an ethnic weighting for Māori and Pacific Islands, indicates the extent to which the school draws its students from low socio-economic communities, with decile 1 being the lowest $10 \%$ and decile 10 the high$\mathrm{est}^{(36)}$. A random number was generated electronically for each school within the Statistical Package for the Social Sciences statistical software package (SPSS Inc., Chicago, IL, USA). Intervention schools within any stratum were selected from highest to lowest random number, and control schools from lowest to highest.

Randomisation of schools for the project was constrained to primary schools (Years 1-6, or Years 1-8). Special schools, intermediate (Years 7 and 8) and restricted composite schools (Years 7-10) were excluded (eight urban, six rural schools). Randomisation to control 
or programme occurred within three types of school, with consideration of ethnicity, location and size:

1. All schools with thirty or more Pacific Islands students (all urban and in the two largest towns; $n$ 9).

2. All other urban schools in the two largest towns (Hamilton City, population 114921 and Tokoroa, urban population 14427; $n$ 34). Urban schools were randomly selected within three 2003 school deciles (1-3, 4-7, 8-10) and two 'size' (below/above median) strata.

3. All other schools were classified as rural ( $n$ 196). It was not possible to stratify by size in the rural areas, so randomisation was stratified by the three decile groupings only. Randomisation in rural areas was originally carried out within the strata of Te Wai o Rona: Diabetes Prevention Strategy, a concurrent, diabetes prevention action research, randomised cluster-controlled trial among adult members of Māori families (generally aged 28 years or above). However, funding was not continued for that trial and the intervention which occurred was not rolled out in a randomised format, so no further adjustment has been made for this.

\section{Enrolment in the evaluation study}

After randomisation, schools were approached for inclusion in the study without knowledge of whether they would be programme or control schools. Where a school declined involvement, the next randomised school was approached.

\section{Sample size}

The primary end point is body composition, including height and weight, girth, upper arm circumference, BMI, BMI $Z$ score, percentage overweight and obese ${ }^{(37)}$, percentage body fat and fat-free mass ${ }^{(38)}$. The prediction equation used for bioelectrical impedance was developed in a similar ethnically diverse population with an $R^{2}$ value of 0.96 and SE of the estimate of $2.44 \mathrm{~kg}$. Ethnicity was not a predictor. At study completion at the end of 2006 there will be four programme and four control groups to compare (programme males and females from entry cohorts of 5 and 10 years, and similar control groups). Assuming a design effect of 2 (for adjustment for clustering), $P<0.05$ and power of $80 \%$, a sample size of 167 children is required to detect a measured change of $0.5 \mathrm{~kg} / \mathrm{m}^{2}$, or forty children are required to detect a measured change of BMI of $1 \cdot 0 \mathrm{~kg} / \mathrm{m}^{2}$. The much larger actual sample size should ensure that power is maintained after accounting for attrition or subgrouping of the data.

\section{Data collection}

Four key data sets were collected at baseline and at 2 years. These included physical measurements of the child, a household questionnaire, a school stock-take, and each child's dental record. In addition, height and weight measures at 6,12 and 18 months were taken for children in the 5-year-old cohort. This was to allow for the possibility of early significant differences in rate and timing of BMI change ('adiposity rebound'(39)) between programme and control groups.

Physical assessments included height measured to $\pm 0.5 \mathrm{~cm}$ (portable height scale PE087; Mentone Education Centre, Victoria, Australia), weight measured to $\pm 0.5 \mathrm{~kg}$ (portable electronic scale TIHD316; Wedderburn, Auckland, New Zealand), hand-to-foot bioelectrical impedance measured at a single frequency $(50 \mathrm{~Hz})$ to $\pm 1 \mathrm{ohm}$ (Imp-DF50 analyser; ImpediMed, Queensland, Australia), upper arm and waist circumference measurements to $\pm 0 \cdot 1 \mathrm{~cm}$, resting blood pressure measured to $\pm 5 \mathrm{mmHg}$ and pulse rate to \pm 10 beats $/ \mathrm{min}$ (Auto Blood Pressure Monitor T8; Omron Corporation, Tokyo, Japan). BMI was calculated as [weight $(\mathrm{kg})] /[\text { height }(\mathrm{m})]^{2}$. BMI $Z$ score was calculated using the CDC 2000 reference population ${ }^{(40)}$. All physical assessments were recorded twice, and a third measure taken where the pre-defined criterion detailed above was exceeded. Two physical fitness assessments (the 2 min sit-to-stand test ${ }^{(41)}$ and the 5 min walk-run test ${ }^{(42)}$ ) were obtained.

All physical baseline measurements were obtained by registered public health nurses, who underwent a training and validation programme, with access to a comprehensive testing manual. Measurements were obtained in the last quarter of 2004, when schools were each visited by teams of two nurses on set days. Consented children who were absent on the day did not have physical assessments completed.

A household questionnaire was sent to and completed by the child's primary caregiver. The questionnaire was split into two key sections. The first gathered information on the carer's ethnicity, household economy, knowledge of nutrition, household food storage and preparation resources. The second section focused on the child. This included questions on the child's ethnicity, eating habits, physical activity, sleep patterns and physical health problems, such as asthma and bone fractures. The household questionnaire was developed for Project Energize from previously validated tools including the National Children's Nutrition Survey ${ }^{(2)}$, the International Study of Asthma and Allergies in Childhood ${ }^{(43)}$, the New Zealand Census $2001^{(44)}$ and selected relevant (to the New Zealand environment) questions from the Pathways physical activity assessment ${ }^{(45)}$. The Pathways physical activity tool was modelled on past surveys and the main aim was to look at the number of activities (sedentary and active) reported. Duration and intensity are difficult to estimate for children; as the aim of the intervention was to increase participation in activity and reduce sedentary time, the questions were selected to be able to measure a change. Ethnicity was self-identified. 
A school stock-take was completed as a structured interview with the school principal or other appropriate staff members. The stock-take provided a profile of the school's nutrition and activity resources, including policies and procedures, transport to and within school, curriculum, canteen, drop-off points, play areas, sports equipment, and the availability of after-school activities. The stock-take questionnaire was based on work by Carter and Swinburn ${ }^{(46)}$. Dental records were provided by the child's dental therapist and used to identify the children's dental health using the standard dmfs/DMFS system $^{(47)}$.

The physical assessment manual, household questionnaire, school stock-take and dental documentation tools are available online (www.projectenergize.co.nz).

\section{Project Energize programme}

Project Energize is a school-based nutrition and activity programme which aims to increase children's activity levels, reduce sedentary time, and optimise nutritional intake through changes in the school environment and culture. Potential benefits of this include increased ability to participate, improved body composition, improved dental health, and improvements in a range of associated health measures. The programme will be described more fully in another publication; however, the basic framework is described here.

Each school programme is individualised to the school, and is based on a needs assessment informed largely by the school's stock-take and individual key priorities identified by the specific school. For example, a school may first prioritise modifying students' nutritional intake, which may take the form of new school policies on food in school, tuck-shop sales, or promoting water intake in school and class. Another school may elect to first prioritise opportunistic activity, which could take the form of developing walking school buses, re-engineering school drop-off zones, refocusing programmed physical activities to increase movement, or programming additional movement sessions within schools. In addition, some activities are uniform across schools, e.g. the 'homeplay challenge', which aims to increase movement and water intake and reduce sedentary time in the home. Finally, children in low-decile schools are provided with daily supplementary fruit and low-fat Ca-enriched cow's milk (Anchor Mega Milk).

'Team Energize' is a group of people specifically recruited and employed to support the delivery and development of the Project Energize programme in each school. Team Energize staff are either teachers or graduates in the fields of exercise and nutrition, with working experience in their field. At induction, they undertake a combined training programme, the components of which include the Health Promoting Schools philosophy of making the school's environment and activities healthpromoting ${ }^{(48)}$, children's nutrition, physical activity, relevant syllabi and available resources, and skills in adult education. This approach has ensured that all Team Energize staff members are able to operate at a similar level of competence, and as a group are able to call upon each other's experience and skills. Each of the eleven Team Energize staff works with about five schools.

Team Energize staff meet regularly for ongoing training and to share their experiences to maximise successful strategies. Staff are led and managed by a Project Energize programme manager (S.M.) who is an experienced community activity and nutrition facilitator.

When a school is enrolled as a programme school, Team Energize staff begin meeting with key people in each school, including senior teaching and administrative staff, school boards, parent representatives and others appropriate to individual schools. This fundamental stage includes a needs assessment (based on the school stocktake) and a goal-setting exercise, to set the general thrust of the activities for each school. Engagement with schools utilises a Health Promoting Schools approach ${ }^{(49)}$, limited only in that the potential activities have to impact either directly or indirectly on the goals of optimising nutrition and activity.

The philosophy adopted is that Team Energize is to act as a change agent, not as additional teaching staff. Thus, for example, Team Energize staff might model classes but would not teach classes instead of the usual class teacher. Where a resource need (such as sporting equipment) is identified, Team Energize would work with the local community networks to secure these.

Control schools were given no additional resources or information; however, no restrictions were placed on initiatives they may pursue for themselves.

School nutrition and activity issues, and action in response to these, will be published elsewhere.

\section{Data analysis}

For the baseline assessments, Project Energize is a crosssectional population survey. The two age groups and sexes will be analysed separately. Analysis software that incorporates stratified and clustered data will be used to obtain estimates with their appropriate confidence intervals. Relative risks of the potential risk factors with the obesity measures will be made using a generalised linear mixed model that incorporates schools as a random effect and control for factors such as ethnicity and school decile as appropriate. The risk factors will be evaluated separately and in combination to ascertain the combined effect on the various outcome measures.

\section{Baseline participation rates}

At randomisation, there were 239 schools in the WDHB region, comprising seventy-four contributing (Year 1-Year 6), 160 full primary (Year 1-Year 8) and five 
Table 2 Project Energize schools and ethnic profile: 2004

\begin{tabular}{|c|c|c|c|c|c|c|c|c|}
\hline & No. of schools & $\%$ of schools & Total no. of children & \% NZ European & \% Māori & $\%$ Pacific Islands & $\%$ Asian & $\%$ Other \\
\hline Total & 124 & 100 & 21870 & 59 & 34 & 4 & 3 & 1 \\
\hline Programme & 62 & 50 & 11090 & 59 & 34 & 4 & 3 & 1 \\
\hline Control & 62 & 50 & 10780 & 59 & 33 & 3 & 3 & 1 \\
\hline Rural & 94 & 76 & 13076 & 66 & 31 & 1 & 1 & 0 \\
\hline Programme & 47 & 76 & 6463 & 64 & 33 & 2 & 1 & 0 \\
\hline Control & 47 & 76 & 6613 & 68 & 30 & 1 & 1 & 0 \\
\hline Urban & 30 & 24 & 8794 & 49 & 37 & 7 & 5 & 1 \\
\hline Programme & 15 & 24 & 4627 & 52 & 35 & 7 & 5 & 1 \\
\hline Control & 15 & 24 & 4167 & 46 & 39 & 7 & 6 & 2 \\
\hline Decile 1-3 & 48 & 39 & 10047 & 37 & 53 & 6 & 3 & 1 \\
\hline Programme & 25 & 40 & 4848 & 35 & 54 & 7 & 3 & 1 \\
\hline Control & 23 & 37 & 5199 & 39 & 52 & 5 & 3 & 1 \\
\hline Decile 4-7 & 41 & 33 & 6557 & 71 & 24 & 2 & 2 & 1 \\
\hline Programme & 21 & 34 & 3575 & 70 & 25 & 2 & 2 & 0 \\
\hline Control & 20 & 32 & 2982 & 71 & 23 & 2 & 2 & 2 \\
\hline Decile 8-10 & 35 & 28 & 5266 & 86 & 8 & 1 & 4 & 1 \\
\hline Programme & 16 & 26 & 2667 & 86 & 8 & 1 & 4 & 1 \\
\hline Control & 19 & 31 & 2599 & 85 & 8 & 1 & 4 & 1 \\
\hline
\end{tabular}

The school decile is the decile of the socio-economic mix of the school. Decile 1 schools are the $10 \%$ of schools with the highest proportion of students from low socio-economic communities, whereas decile 10 schools are the $10 \%$ of schools with the lowest proportion of these students. The Ministry of Education calculates socio-economic decile scores from five Census elements: household income; occupation; household crowding; educational qualifications; and income support ${ }^{(50)}$.

composite comprehensive (Years 1-13). Our initial randomisation procedure selected 125 schools. Fourteen randomised schools declined to participate, and were replaced through the randomisation protocol. One replacement school subsequently withdrew, leaving sixty-two schools in the programme group and sixty-two schools in the control group. This is shown in Table $2^{(50)}$, along with the ethnic composition and distribution of the schools. Table 3 shows the consent rates for 5- and 10-year-old children invited to participate in the evaluation, enrolment numbers, and characterisation by location (urban, rural) and school decile, for both programme and control schools.

\section{Discussion}

We have developed a randomised controlled study of through-school nutrition and activity interventions, with outcome measures including change in practice, change in nutrition and activity, and change in body composition and other health parameters.

It might be argued that a complex programme where interventions at the school level vary between schools is not suitable for a randomised study. However, as discussed elsewhere ${ }^{(51)}$, we believe that the key standardisation is the process for developing and implementing interventions, and that it is this which we are evaluating. This is expected to lead to a range of interventions, some of which are common to many or all involved schools.

One of our key end points is body composition, for which we had to determine optimal $v$. achievable measures. While BMI is usually taken as the lingua franca, this is problematic as the relationship between fat-free mass, height and percentage body fat (for which BMI is often taken as a proxy) changes over childhood. Furthermore, different children may have the same BMI but radically different body compositions in terms of fat-free mass and percentage body fat ${ }^{(52)}$. Thus while BMI is good for population-level measures, measuring change in body composition requires tools such as bioelectrical impedance analysis and dual-energy X-ray absorptiometry (DEXA), which are likely to show significance and regional body composition changes even where BMI does not. In-thefield assessment of longitudinal changes in body composition parameters requires population measures of body composition validated by standards such as DEXA and isotope dilution. In-the-field assessment should have little discomfort, be safe, quick and reliable, and be measured in tandem with other health indicators such as waist, fitness, blood pressure and heart rate, to look at more than just the fat content. It is important to have precision of measurements so that change can be measured in intervention studies and therefore associated with concurrent behavioural and environmental changes.

We have restricted our study groups to 5- and 10-yearold entry cohorts. We selected the 5-year-old entry cohort with the intention of identifying the mid-childhood rise in BMI at 5-7 years of age, also known as the adiposity rebound. Both the timing of the adiposity rebound and the rate of body mass centile crossing are predictors of later obesity ${ }^{(53)}$. Further, the period around the adiposity rebound has been identified as a critical period for later adult morbidity and mortality ${ }^{(19)}$. Potentially, one indicator of an effective programme would be a relatively later adiposity rebound or a difference in body mass centile crossing, in programme compared with control children. Against this, the adiposity rebound may already be programmed by genetic, in utero and early childhood experience and could have occurred before age 5 in some 


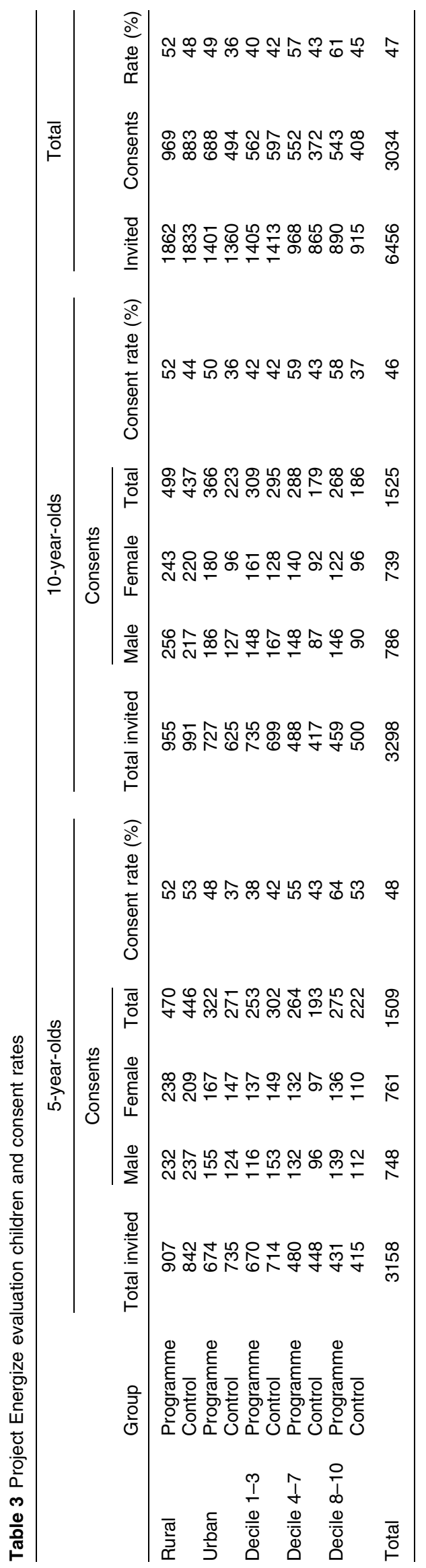

of the more obese children. Similarly, in a significantly affected population, the adiposity rebound may be occurring too early for a programme commencing at school entry to be effective.

The 10-year-old cohort was selected because they will allow us to evaluate the potential for intervention over transition into early puberty. This is a time when developmental challenges occur including individuation, separation and identification, and has also been identified as a potential critical period for adult morbidity and mortality ${ }^{(19,54)}$.

The sample size for this project is similar to both the New Zealand Child and Youth Nutrition Survey ${ }^{(2)}$ and the West Australian Child and Adolescent Physical Activity and Nutrition Survey ${ }^{(55)}$, which are both cross-sectional surveys. However, the present intervention study has far more children and more 5- and 10-year-olds than either of these previous studies.

Our stratified randomisation was based on known local and New Zealand demographic data. While recognising that there is changing cultural awareness of activity and nutrition issues, and that schools may be changing practices in this area, we felt in this translational research that it was important to determine whether the Project Energize programme provided benefits over and above any changes that would ordinarily be occurring in schools over the period. As such, we placed no restriction on activities of the control groups, and we will be evaluating change in the control schools from baseline.

The overall consent rate was $48 \cdot 1 \%$, which is consistent with previous large longitudinal studies ${ }^{(56)}$ and with other current studies ${ }^{(57)}$, and while our randomisation procedure gave sufficient numbers for our power analysis, enrolment numbers skewed to rural. It must be stressed that our study cohorts are in an environment where all children in the school are receiving the intervention or control, and the study populations are simply representatives of a wider pool who are receiving the additional resourcing, as is appropriate with health funding. The Ethics Committee requirement for younger children to sign their own informed consent may have impacted on consent rate. Subsequent dialogue with the Ethics Committee has (for future studies) replaced the requirement for younger children to sign informed consent with a process for parents to provide consent on their children's behalf, in the manner of an incapacitated person.

This evaluation has limitations due to the dynamics of the environment in which it is conducted. As mentioned previously, the Waikato region had two major population health initiatives - Te Wai o Rona: Diabetes Prevention Strategy and Project Energize. This introduced the challenge of preventing each from contaminating the evaluation of the other. However, the two programmes were delivered in different ways. Te Wai o Rona: Diabetes Prevention Strategy specifically targeted adult Māori, and 
was a community-based initiative delivered largely through Māori-specific community organisations and structures, and not in the school setting. Project Energize is delivered only through schools, but does reach through to the family and community from the schools. In the event, Te Wai o Rona: Diabetes Prevention Strategy was not continued for funding reasons; full roll-out of that intervention did not occur, and we feel it unlikely that this would impact on Project Energize. Even so, the clusters used for randomisation and strata will be included in the analyses to allow adjustment and for possible contamination to be investigated.

Our cluster analysis will be by intention to treat; however, during the 2-year project it is inevitable that some children and staff will move school. This is most likely to occur with the 10-year-old sample as some move on to intermediate schools. Significant movement among the 10-year-old cohort may warrant a cross-sectional analysis involving comparisons between a sample of 10-year-olds from both the control and programme schools after 2 years. We are tracking movements of study children and school principals between programme, control and other schools. This may allow additional analysis of dose effect.

We are interested in a number of secondary end points, both in terms of: (i) identifying potentially modifiable contributors to decreased activity, increased sedentary time and poor nutrition; and (ii) evaluating the potential for Project Energize to change these and associated outcomes. These end points include differences in aspects of body composition and proportions, dentition, bone mineralisation, asthma, and school performance. Our current data sets have limited information on these, but the study retains potential for cross-sectional end-point analysis. Our evaluation does not include any blood or urine testing at baseline. While this would be desirable to expand secondary end-point evaluation, we took a pragmatic decision not to pursue this based on a tight timeline for baseline measurement, likely reduction in baseline study enrolment, and increased complexity for the ethics committee application. The basic design of the Project Energize evaluation is a cluster-randomised, controlled longitudinal study. This does provide a platform that can enable other research. This may include qualitative research, and cross-sectional end-point studies.

The prevalence of obesity, now the number one public health priority in New Zealand, and its secondary morbidities, and the associated decrease in personal and community capacities, is increasing at an accelerating rate. Increasingly, there are moves afoot to invest large amounts of money in intervention programmes, without solid evidence as to what works. The present evaluation will provide evidence of what is effective, practical and affordable in the school setting while also determining what is ineffective, impractical or uneconomic, thus helping direct public money and effort into best practice.

\section{Acknowledgements}

The Waikato District Health Board funds the Project Energize programme and its evaluation. Fonterra Brands NZ supplies milk to targeted programme schools. The New Zealand Ministry of Health and the Perry Foundation have provided funding for provision of fruit to targeted programme schools, and the Ministry of Health has contributed to evaluation funding.

\section{References}

1. Ogden CL, Carroll MD \& Flegal KM (2003) Epidemiologic trends in overweight and obesity. Endocrinol Metab Clin North Am 32, 741-760.

2. Parnell W, Soragg R, Wilson N, Schaaf D \& Fitzgerald E (2003) NZ Food NZ Children: Key Results of the 2002 National Children's Nutrition Survey. Wellington: Ministry of Health.

3. Turnbull A, Barry D, Wickens K \& Crane J (2004) Changes in body mass index in 11-12-year-old children in Hawkes Bay, New Zealand (1989-2000). J Paediatr Child Health 40, 33-37.

4. Nelson N (2005) Influences in Childhood on the Development of Cardiovascular Disease and Type 2 Diabetes in Adulthood. Wellington: Ministry of Health.

5. Rose D \& Bodor JN (2006) Household food insecurity and overweight status in young school children: results from the Early Childhood Longitudinal Study. Pediatrics 117, 464-473.

6. Nesbitt SD, Ashaye MO, Stettler N, Sorof JM, Goran MI, Parekh R \& Falkner BE (2004) Overweight as a risk factor in children: a focus on ethnicity. Ethn Dis 14, 94-110.

7. Tyrrell VJ, Richards GE, Hofman P, Gillies GF, Robinson E \& Cutfield WS (2001) Obesity in Auckland school children: a comparison of the body mass index and percentage body fat as the diagnostic criterion. Int J Obes Relat Metab Disord 25, 164-169.

8. Wilson P, O'Meara S, Summerbell C \& Kelly S (2003) The prevention and treatment of childhood obesity. Qual Saf Health Care 12, 65-74.

9. Doyle R (2006) Sizing up. Sci Am 294(2), 32.

10. Tomkins A (2001) Vitamin and mineral nutrition for the health and development of the children of Europe. Public Health Nutr 4, 91-99.

11. Winkleby MA, Feldman HA \& Murray DM (1997) Joint analysis of three US community intervention trials for reduction of cardiovascular disease risk. J Clin Epidemiol 50, 645-658.

12. Porte Jr D, Seeley RJ, Woods SC, Baskin DG, Figlewicz DP \& Schwartz MW (1998) Obesity, diabetes and the central nervous system. Diabetologia 41, 863-881.

13. Leibel RL, Rosenbaum M \& Hirsch J (1995) Changes in energy expenditure resulting from altered body weight. $N$ Engl J Med 332, 621-628.

14. Gale SM, Castracane VD \& Mantzoros CS (2004) Energy homeostasis, obesity and eating disorders: recent advances in endocrinology. J Nutr 134, 295-298.

15. Swinburn BA, Caterson I, Seidell JC \& James WP (2004) Diet, nutrition and the prevention of excess weight gain and obesity. Public Health Nutr 7, 123-146. 
16. Salmon J \& King A (2005) Population approaches to increasing physical activity among children and adults. In Obesity Prevention in the 21st Century: Public Health Approaches to Tackle the Obesity Epidemic, pp. 129-152. [D Crawford and R Jeffrey, editors]. Oxford: Oxford University Press.

17. Novilla ML, Barnes MD, De La Cruz NG, Williams PN \& Rogers J (2006) Public health perspectives on the family: an ecological approach to promoting health in the family and community. Fam Community Health 29, 28-42.

18. Dietz WH (1994) Critical periods in childhood for the development of obesity. Am J Clin Nutr $\mathbf{5 9}$ 955-959.

19. Cameron N \& Demerath EW (2002) Critical periods in human growth and their relationship to diseases of aging. Am J Phys Anthropol Suppl. 35, 159-184.

20. Power C \& Parsons T (2000) Nutritional and other influences in childhood as predictors of adult obesity. Proc Nutr Soc 59, 267-272.

21. Summerbell CD, Waters E, Edmunds LD, Kelly S, Brown T \& Campbell KJ (2005) Interventions for preventing obesity in children. Cochrane Database Syst Rev (3), CD001871.

22. McKenzie TL, Sallis JF, Prochaska JJ, Conway TL, Marshall SJ \& Rosengard P (2004) Evaluation of a two-year middleschool physical education intervention: M-SPAN. Med Sci Sports Exerc 36, 1382-1388.

23. Sallis J, McKenzie TL, Alcaraz JE, Kolody B, Faucette N \& Hovell MF (1997) The effects of a 2-year physical education program (SPARK) on physical activity and fitness in elementary school students. Sports, Play and Active Recreation for Kids. Am J Public Health 87, 1328-1334.

24. Sallis JF, McKenzie TL, Kolody B, Lewis M, Marshall S \& Rosengard P (1999) Effects of health-related physical education on academic achievement: project SPARK. Res Q Exerc Sport 70, 127-134.

25. Williams CL, Bollella MC, Strobino BA, Spark A, Nicklas TA, Tolosi LB \& Pittman BP (2002) 'HealthyStart': outcome of an intervention to promote a heart healthy diet in preschool children. J Am Coll Nutr 21, 62-71.

26. Vandongen R, Jenner DA, Thompson C, Taggart AC, Spickett EE, Burke V, Beilin LJ, Milligan RA \& Dunbar DL (1995) A controlled evaluation of a fitness and nutrition intervention program on cardiovascular health in 10- to 12-year-old children. Prev Med 24, 9-22.

27. Burke V, Thompson C, Taggart AC, Spickett EE, Beilin LJ, Vandongen R, Milligan RA \& Dunbar DL (1996) Differences in response to nutrition and fitness education programmes in relation to baseline levels of cardiovascular risk in 10 to 12-year-old children. J Hum Hypertens 10, Suppl. 3, S99-S106.

28. Burke V, Milligan RA, Thompson C, Taggart AC, Dunbar DL, Spencer MJ, Medland A, Gracey MP, Vandongen R \& Beilin LJ (1998) A controlled trial of health promotion programs in 11-year-olds using physical activity 'enrichment' for higher risk children. $J$ Pediatr 132, 840-848.

29. James J, Thomas P, Cavan D \& Kerr D (2004) Preventing childhood obesity by reducing consumption of carbonated drinks: cluster randomised controlled trial. BMJ 328, 1237.

30. Sahota P, Rudolf MC, Dixey R, Hill AJ, Barth JH \& Cade J (2001) Randomised controlled trial of primary school based intervention to reduce risk factors for obesity. BMJ $\mathbf{3 2 3}$, 1029-1034

31. Yin $\mathrm{Z}$, Gutin $\mathrm{B}$, Johnson $\mathrm{MH}$, Hanes $\mathrm{Jr} \mathrm{J}$, Moore JB, Cavnar M, Thornburg J, Moore D \& Barbeau P (2005) An environmental approach to obesity prevention in children: Medical College of Georgia FitKid project year 1 results. Obes Res 13, 2153-2161.
32. Mukoma W \& Flisher AJ (2004) Evaluations of health promoting schools: a review of nine studies. Health Promot Int 19, 357-368.

33. Ministry of Health (2003) Healthy Eating - Healthy Action Oranga Kai - Oranga Pumau: A Strategic Framework. Wellington: Ministry of Health.

34. Craig E (2005) The Health Status of Children and Young People in the Waikato. Auckland: New Zealand Child and Youth Epidemiology Service.

35. Salmond C \& Crampton P (2002) NZDep2001 Index of Deprivation. Wellington: Department of Public Health, Wellington Schools of Medicine and Health Sciences.

36. Ministry of Education (2007) Deciles information. http:// www.minedu.govt.nz/index.cfm?layout $=$ document\&docu mentid $=7693$ (accessed July 2007)

37. Cole TJ, Bellizzi MC, Flegal KM \& Dietz WH (2000) Establishing a standard definition for child overweight and obesity worldwide: international survey. BMJ 320, 1240-1243.

38. Rush EC, Puniani K, Valencia ME, Davies PS \& Plank LD (2003) Estimation of body fatness from body mass index and bioelectrical impedance: comparison of New Zealand European, Maori and Pacific Island children. Eur J Clin Nutr 57, 1394-1401.

39. Williams SM (2005) Weight and height growth rate and the timing of adiposity rebound. Obes Res 13, $1123-1130$.

40. Ogden CL, Kuczmarski RJ, Flegal KM, Mei Z, Guo S, Wei R, GrummerStrawn LM, Curtin LR, Roche AF \& Johnson CL (2002) Centers for Disease Control and Prevention 2000 growth charts for the United States: improvements to the 1977 National Center for Health Statistics version. Pediatrics 109, 45-60.

41. Bohannon RW (1995) Sit-to-stand test for measuring performance of lower extremity muscles. Percept Mot Skills 80, 163-166.

42. MacNaughton L, Croft R, Pennicott J \& Long T (1990) The 5 and 15 minute runs as predictors of aerobic capacity in high school students. J Sports Med Phys Fitness 30, 24-28.

43. Asher M, Keil U, Anderson HR et al. (1995) International Study of Asthma and Allergies in Childhood (ISAAC): rationale and methods. Eur Respir J 8, 483-491.

44. Statistics New Zealand (2007) The New Zealand Census 2001. http://www.stats.govt.nz/census/default.htm (accessed July 2007).

45. Going SB, Levin S, Harrell J, Stewart D, Kushi L, Cornell CE, Hunsberger S, Corbin C \& Sallis J (1999) Physical activity assessment in American Indian schoolchildren in the Pathways study. Am J Clin Nutr 69, 4 Suppl., 788S-795S.

46. Carter M-A \& Swinburn B (2004) Measuring the 'obesogenic' food environment in New Zealand primary schools. Health Promot Int 19, 15-20.

47. Schuller AA \& Holst D (2001) Oral status indicators DMFT and FS-T: reflections on index selection. EurJ Oral Sci 109, $155-159$.

48. St Leger LH (1999) The opportunities and effectiveness of the health promoting primary school in improving child health - a review of the claims and evidence. Health Educ Res 14, 51-69.

49. Lister-Sharp D, Chapman S, Stewart-Brown S \& Sowden A (1999) Health promoting schools and health promotion in schools: two systematic reviews. Health Technol Assess 3, 22, 1-207.

50. Ministry of Education (2005) School Leavers Attainment 2004 Data Cubes User Guide. Wellington: Ministry of Education.

51. Hawe P, Shiell A \& Riley T (2004) Complex interventions: how 'out of control' can a randomised controlled trial be? BMJ 328, 1561-1563. 
52. Wells JC (2000) A Hattori chart analysis of body mass index in infants and children. Int J Obes Relat Metab Disord 24, 325-329.

53. Cole TJ (2004) Children grow and horses race: is the adiposity rebound a critical period for later obesity? $B M C$ Pediatr 4, 6.

54. Daniels JA (1990) Adolescent separation-individuation and family transitions. Adolescence 25, 97, 105-116.

55. Hands B, Parker H, Glasson C, Brinkman S \& Read H (2004) Physical Activity and Nutrition Levels in Western
Australian Children and Adolescents: Report. Perth: Western Australian Government.

56. Silva P \& McCann M (1996) An introduction to the Dunedin study. In From Child to Adult, pp. 1-23 [P Silva and W Stanton, editors]. Auckland: Oxford University Press.

57. Yin Z, Hanes J Jr, Moore JB, Humbles P, Barbeau P \& Gutin B (2005) An after-school physical activity program for obesity prevention in children: the Medical College of Georgia FitKid Project. Eval Health Prof 28, 67-89. 